\title{
United Nations Regional Centre for Space Science and Technology Education in Africa: Achievements, Opportunities, Challenges, and the Future
}

\author{
Ganiyu I. Agbaje \\ African Regional Centre for Space Science and Technology Education in English (ARCSSTE-E), Ile-Ife, Nigeria
}

Copyright $\bigcirc 2017$ by authors, all rights reserved. Authors agree that this article remains permanently open access under the terms of the Creative Commons Attribution License 4.0 International License

\begin{abstract}
Capacity building in Space Science and Technology as well as enhancement and retention of existing capacity, are critical for developing competencies to efficiently respond to societal challenges and addressing sustainable development. Following the UN General Assembly resolutions $37 / 90$ of 10th December 1982 (UNISPACE), and $45 / 72$ of 11 December, 1990 (UN-COPUOS), the UN-OOSA established the Regional Centers for Space Science and Technology Education in 1995. To date six (6) Regional Centers have been established with the main aim to build a high quality capacity and critical mass of indigenous Space Scientists/Educators in developing countries for the development and application of Space Science \& Technology for Sustainable National \& Regional Development. African Regional Centre for Space Science and Technology Education has been established in Africa since 1998. This paper describes the achievements of the Centre since inception through their Postgraduate and Outreach programs. It is, however, observed that Member States have not optimally worked together to maximally utilize the opportunities that this Regional Centre present. By highlighting the capabilities of the Centre, the future plans for harnessing the human potential available for the next generation in Africa are discussed. Argument was made for the need for integrated space technology and applications to be domesticated at the UN regional Centers for ease of access to best practice and fast-track sustainable developments and regional collaborations. In conclusion, the challenges of the Centre, which in turn impact on the local space workforce, are mentioned and recommendations are made to this effect.
\end{abstract}

Keywords United Nations, Space Science \& Technology, Capacity Building, Outreach

\section{Introduction}

The exponential growth of scientific knowledge and continuing development in technology are transforming the society daily. Our lives and future depend profoundly on our understanding of planet Earth. Space technology enables us to observe possible threats to life on Earth and has tools to help inhibit them. Our Knowledge about space increased through scientific studies can have enormous economic and social benefits that could contribute to meeting many societal needs, from human security to sustainable development.

Age of space technology has become a significant part of our daily lives. Owing to the rewards and opportunities afforded by space technology and science and their use in promoting social and economic development and looking at possibilities to enable development in nations, also to have access to space technology tools by strengthening their indigenous capacities in this field, the United Nation, through its Office for Outer Space Affairs, facilitated the establishment and operation of the Regional Centres for Space Science and Technology Education, affiliated to the United Nations.

According to [7] capacity building could be defined as the sum total of a country's human, scientific, technological, organization to reduce the level of risk, it is the development of facilities, programs or other resources which help develop a community's (organization or group) ability to perform specific tasks. A fundamental goal of capacity building is to enhance the abilities of stakeholders to evaluate and address crucial questions related to policy choices and modes of implementation among different options for development. These could be based on the understanding of the environmental potential and limits and of the needs that is needed by the people of the country concerned.

Capacity building in Space Science and Technology as well as enhancement and retention of existing capacity, are critical for developing competencies to efficiently respond to societal challenges and addressing sustainable development. To meet the Sustainable Development Goals (SDGs 2030), Africa needs to build and strengthen her capacity to assimilate and generate knowledge for sustainable 
development.

The dearth of the technical know-how to participate independently in space-related activities by Africans is a major challenge in our sustainable development planning decisions and actions, which are not from a technically informed position about the environment. A society's control over her environment brings about increased realization of her values, leading to socio-economic advancement, security, and improved wellbeing of her people.

We therefore need to make the utmost use of every capacity building opportunities that presents itself in the field of Space Science and Technology in other to provide solutions to our sustainable development challenges. The United Nations based on the General Assembly resolutions and realising the importance of capacity building in this field especially for the developing countries and nations with economies in transition has in the last 21 years established six Regional Space Science and Technology Education Centres. Two of these Centres are in Africa located in Nigeria (for the Anglophone countries) and Morocco (for the francophone countries).

This paper reviewed the 18 years of the existence of one of the Africa's Centre - the African Regional Centre for Space Science and Technology Education in English [ARCSSTE-E]. Starting with her missions, mandates, and achievements to date; available opportunities for member countries; challenges, and concluded with recommendations for the future.

\section{Establishment of ARCSSTEE}

The African Regional Centre for Space Science and Technology in English (ARCSSTE-E) was one of the Centres established following the United Nations General Assembly resolution 37/90 of 10th December 1982 UNISPACE' 82 sponsored [4] and further rekindled by UN-COPUOS sponsored General Assembly resolution 45/72 of 11th December, 1990 (United Nations, 1990) for the establishment of such institutions by $\mathrm{UN}$ in existing national/regional educational institutions in developing countries (Box 1).

The six Regional Centres established are located in Africa (Nigeria and Morocco (2)); Mid-East (Jordan - 1); Asia (India and China (2); and South America (1 with campuses Mexico and Brazil -). See Box 2 and Figure 1.

The African Regional Centre for Space Science and Technology Education - English (ARCSSTE-E) located at Obafemi Awolowo University, Ile-Ife, Nigeria was established under the auspices of the United Nations Office for Outer Space Affairs (UNOOSA), Vienna, Austria, and was formally inaugurated on the 24th of November, 1998. ARCSSTE-E has the mandate to train educators in English-speaking African countries (24) (Figure 2) on application of Space Science and Technology for sustainable national, regional and continental development. It also serves as an activity Centre for the National Space Research and Development (NASRDA), Nigeria following her establishment in 1999.

$$
\begin{aligned}
& \text { United Nations General Assembly Resolutions } \\
& \text { - } 37 / 90 \text { of } 10^{\text {th }} \text { December } 1982 \text { - UNISPACE' } 82 \\
& \text { 'That the United Nations Office for Outer Space Affairs (UNOOSA), through its Programme on } \\
& \text { Space Applications should focus its attention, inter alia, on building of indigenous capacities for } \\
& \text { the development and utilization of Space Science and Technology, particularly at the local } \\
& \text { level }^{\prime} \\
& \text { - 45/72 of } 11 \text { December, } 1990 \text { - UN-COPUOS } \\
& \text { 'That the UN should lead, with the active support of its specialized agencies and other } \\
& \text { international organisations, an international effort to establish Centres for Space Science and } \\
& \text { Technology Education at the regional level in existing national/regional educational } \\
& \text { institutions in the developing countries' }
\end{aligned}
$$

Box 1. United Nations Resolutions establishing the UN Regional Centres for Space Science \& Technology Education 
$\oplus$ Africa:

- Nigeria - African Regional Centre for Space Science \& Technology Education English [ARCSSTE-E] - 1998

- Morocco - African Regional Centre for Space Science \& Technology Education - in French Language (CRASTE-LF) - 1998

$\oplus$ Middle - East:

- Jordan- Regional Centre for Space Science \& Technology Education for Western Asia (RCSSTEWA) - 2012

Asia:

- India - Centre for Space Science \& Technology Education in Asia and the Pacific (CSSTEAP) - 1995

- China - Regional Centre for Space Science \& Technology Education in Asia and the Pacific (RCSSTEA) - 2014

$\rightarrow$ South America: 2 Campuses

- Mexico- Regional Centre for Space Science \& Technology Education for Latin America and \& the Caribbean (CRECTEALC) - 2003

- Brazil - Regional Centre for Space Science \& Technology Education for Latin America and \& the Caribbean (CRECTEALC) - 2003

Box 2. Regional Canters and location countries

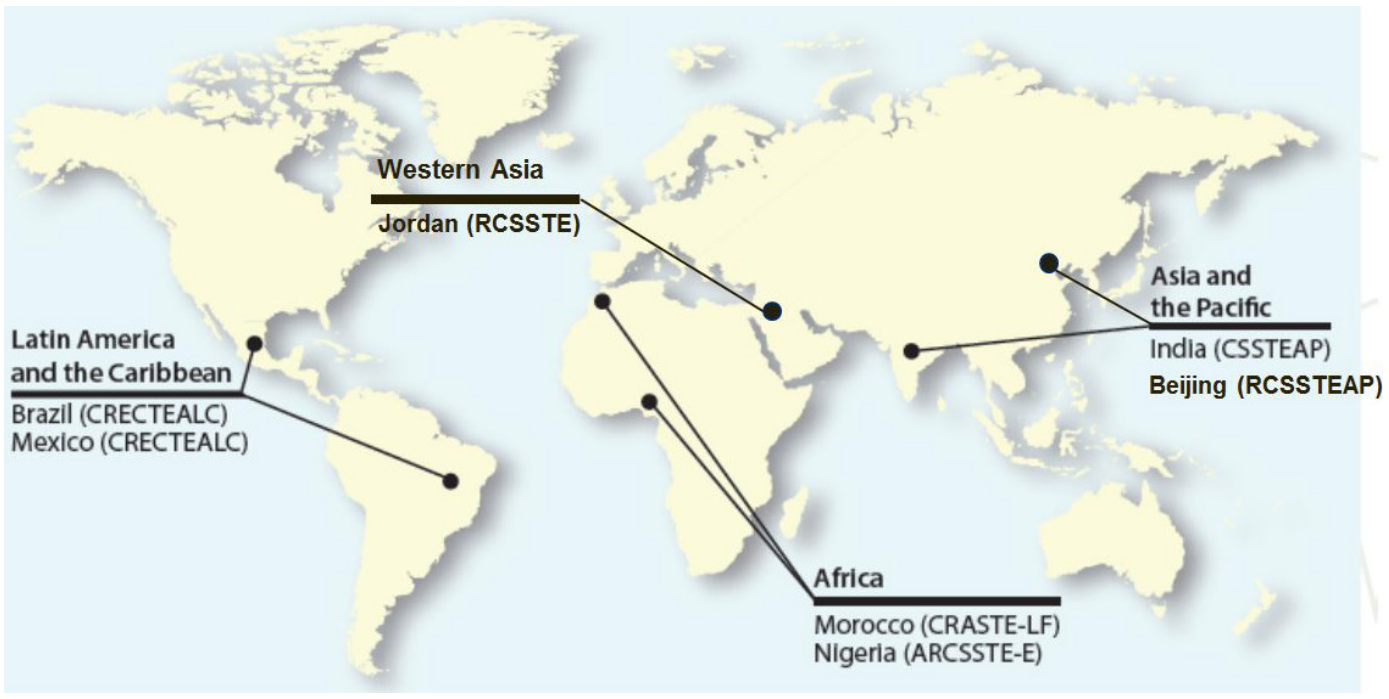

Figure 1. UN Regional Centres Location Map 


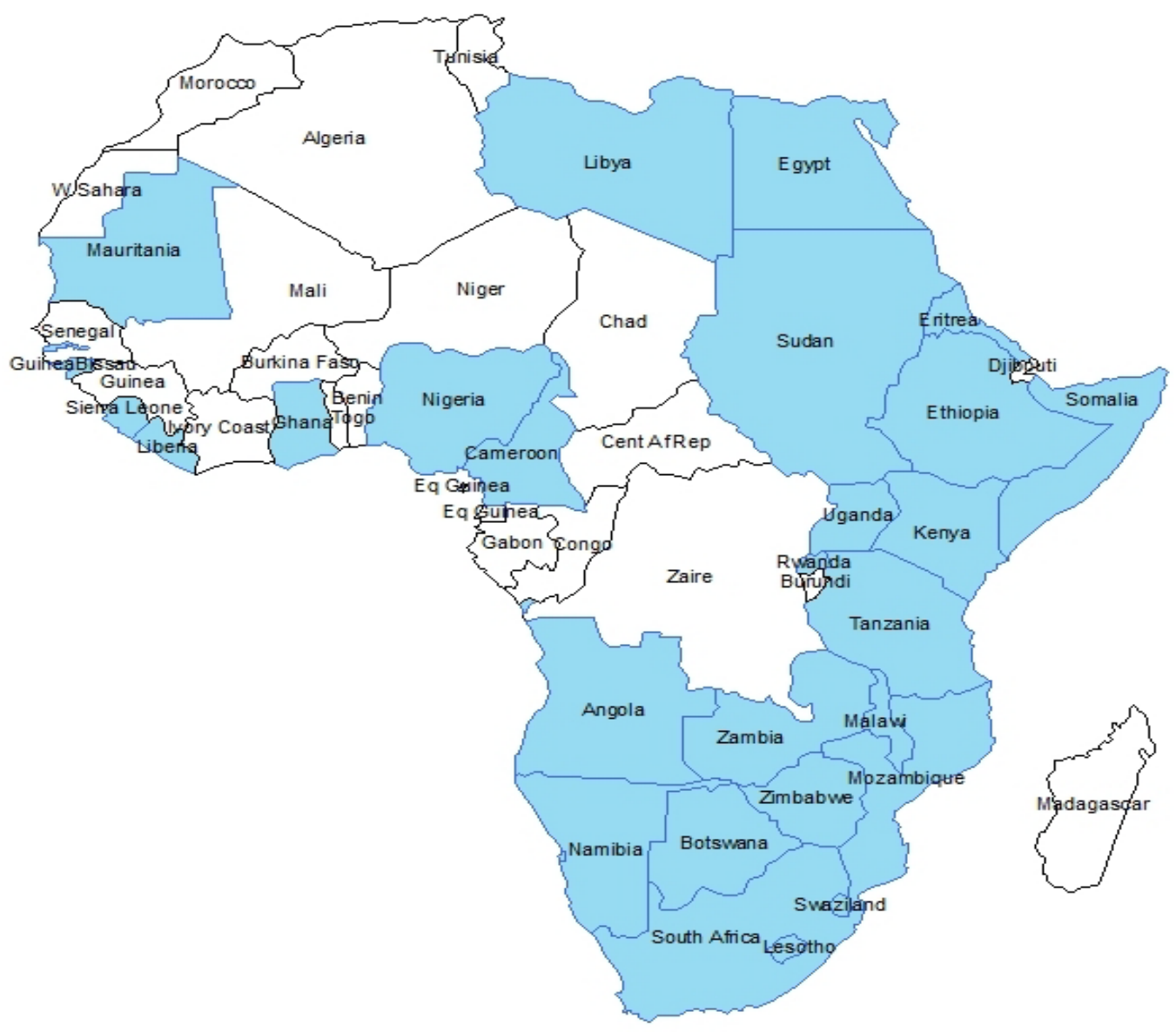

Legend

English Speaking Nations

Figure 2. ARCSSTE-E Member States

The Centre trains participants mainly from English speaking African countries: Angola, Botswana, Cameroon, Egypt, Ethiopia, Ghana, Kenya, Lesotho, Liberia, Malawi, Mozambique, Namibia, Nigeria, Sierra Leone, South Africa, Sudan, Swaziland, Tanzania, The Gambia, Uganda, Mauritania, Zambia, Somalia, and Zimbabwe.

\section{Goals and Objectives of ARCSSTE-E's Capacity Building Program}

\subsection{Vision}

The vision of ARCSSTE-E is the development of human resources and creation of public awareness on the benefits and applications of space science and technology for sustainable development of the African region and improvement of the quality of life of the people, through rigorous education/training and outreach programmes thereby empowering and informing the people on Space for Development.

\subsection{Objectives}

The objectives of ARCSSTE-E are:

- Development of skills and knowledge of university educators, research application scientists through rigorous theory and research works, applications, field exercises, and Pilot-Projects in aspects of Space Science and Technology, especially in five principal areas:

- Remote Sensing \& GIS

- Basic Space \& Atmospheric Science (BSAS)

- Satellite Communications

- Satellite Meteorology

- GNSS

- To establish academic relationships with space-related institutions, as well as regional and international cooperation in space science and technology programmes.

- To establish space education outreach programmes for the dissemination of the values of space science \& technology to pupils/students and teachers at primary, 
secondary, and tertiary institutions, policy and decision makers and the general public.

ARCSSTE-E therefore aims to achieve her mandate through the Postgraduate programmes; Space Education Outreach Programme (SEOP); and the Space-based Research and Development.

\section{ARCSSTE-E Core Programs}

\subsection{Post Graduate Diploma Program}

Postgraduate courses provided by all the UN-affiliated Regional Centres are based on education curricula developed through UN Expert meetings, with the support of prominent educators (Haubold, 2003a, 2003b). The Expert meetings were always called to develop, revise, and update existing education curricula. The last meeting was held 2011 which saw the introduction of Global Navigation Satellites System (GNSS) as a core option.

The Post-Graduate Diploma (PGD) Programme which is of 9-months duration is offered in the five key areas of Space Science and Technology (SST) Education as explained earlier. Under this programme, International participants are offered full scholarship covering: tuition fee, accommodation, medical services, return travel ticket, and monthly stipend. Nigeria bears all these cost except the return ticket provided for by UN-OOSA.

From 2001 to date a total of 404 participants from 17 countries had completed the PGD programme. Figure 3 and Figure 4 shows the annual distribution of participants from 2001 to 2016 and their distribution by course options respectively.

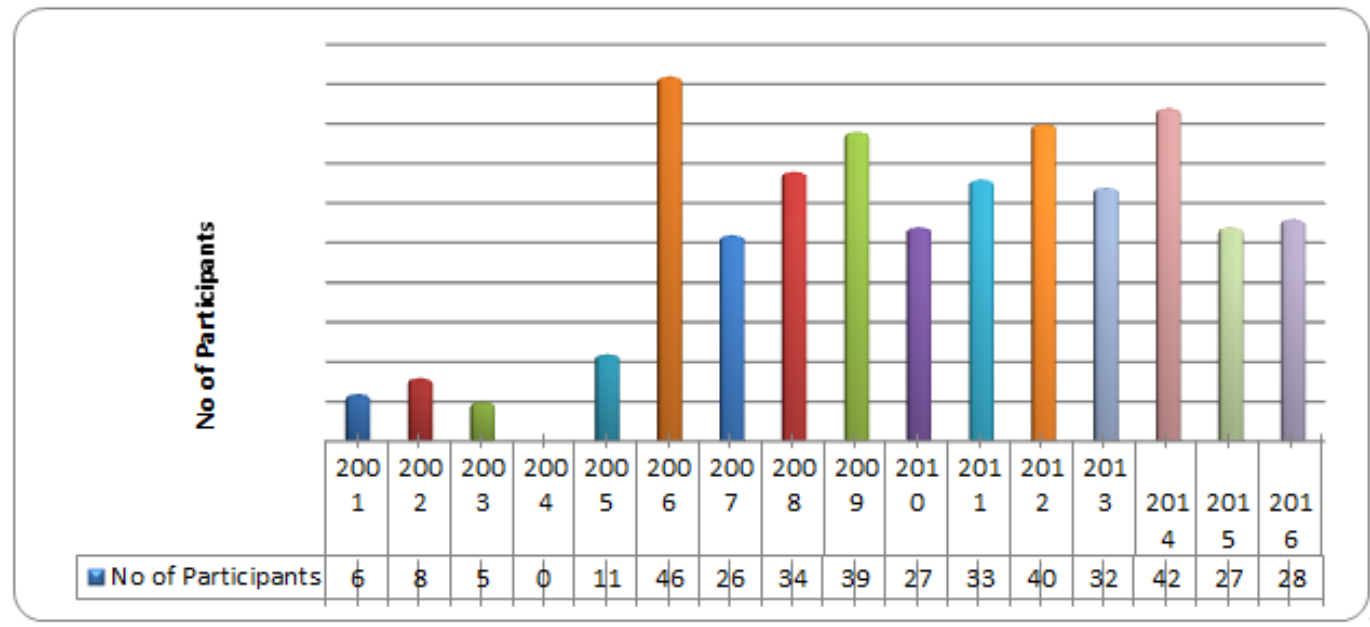

DISTRIBUTION OF PGD PARTICIPANTS BY COURSE OPTIONS (2001 - 2016)

Figure 3. Annual Distribution of PGD Participants (2001-2016)

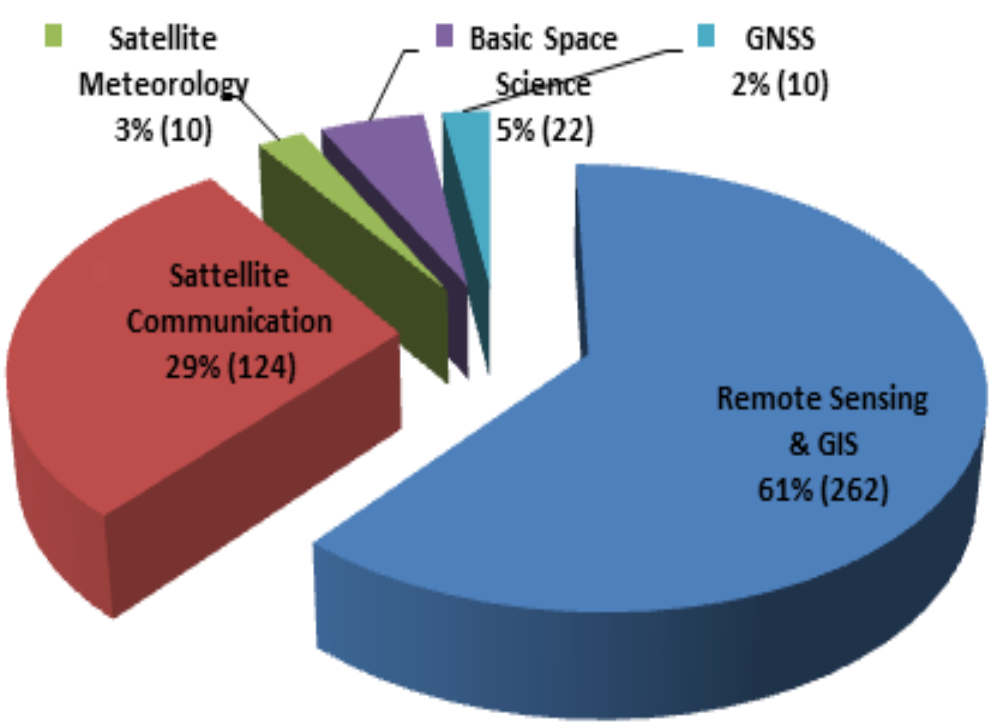

Figure 4. Participants by Course options 
Applicants are expected to have a minimum of a Bachelor's degree or HND from an internationally recognized university/institution before they can be enrolled in this programme.

\subsection{Tech. (Space Science \& Technology Applications)}

ARCSSTE-E runs an 18 months Masters programme in Space Science and Technology (MSST) in collaboration with the Federal University of Technology, Akure, Nigeria, in the all science and technology core space areas. The MTech. is an 18-months full-time programme made up of two semesters of course work and a semester of intensive research work. The programme which commenced in 2013 has 18, 15, 20 participants in 2013, 2014, and 2015 respectively.

\subsection{Space Education Outreach Program (SEOP)}

Space Education Outreach Programme (SEOP) is one of the avenues through which the mission of the Centre is being accomplished. The SEOP is aimed at stimulating the interest of students and teachers in primary, secondary, tertiary institutions and the general public in space science and technology. This has resulted in the creation of Space Clubs and Mentorship programmes to consolidate what the participants have learnt in the programmes.

Some of the activities carried out under the Space Education Outreach Programme are:

\subsubsection{Space Education Workshops (SEW)}

Designed to educate and also inspire participants on the benefit of space science and technology and in the process engender interest in Science, Technology, Engineering and Maths (STEM). An example of activities that have been carried out in this regard in primary and secondary schools is the Workshop on Astronomy held in 2015 titled "Twinkle Twinkle Little Star: Promoting Astronomy (Outer Space) among School Children"'. Participants had the opportunity to view astronomical events online, through a robotic telescope service coordinated under the SLOOH Project (see Figure 4).

\subsubsection{World Space Week (WSW) Celebration}

Celebrated annually in line with the United Nations General Assembly resolution of 6 December 1999 declaring 4 to 10 October every year as World Space Week to celebrate at the international level the contributions of space science and technology to the betterment of the human condition [5] [6].

\subsubsection{Workshops on Robotics}

This innovative scheme was introduced, in collaboration with the Internet Laboratory of Obafemi Awolowo University (iLab-OAU) into the outreach program of the ARCSSTE-E in 2011 through the Robotics Education Program (REP). The aims of REP are among others to foster creative thinking and develop problem solving skills using hands-on approach to promote scientific inquiry learning, cultivate mentorship skills from tertiary to primary educational levels, inculcate collaborative thinking and develop team spirit among youths. The REP has resulted in the Centre's participation for the first time, in the World Robot Olympiad, held in Abu Dhabi, United Arab Emirates in 2011 .

\subsubsection{Space Clubs}

ARCSSTE-E has established over 100 Space Clubs in various tertiary and secondary schools especially in Nigeria.

\subsubsection{United Nations "Zero Gravity Instrument Project" (ZGIP)}

Is meant to promote space education and research in microgravity among pre-collegiate youths using Clinostats distributed under the United Nations Human Space Technology Initiative (UN-HSTI) Zero-Gravity Instrument Project (ZGIP) (Figure 5). In addition, the Centre has participated thrice in the human Zero-G program since 2006 (Figure 6).

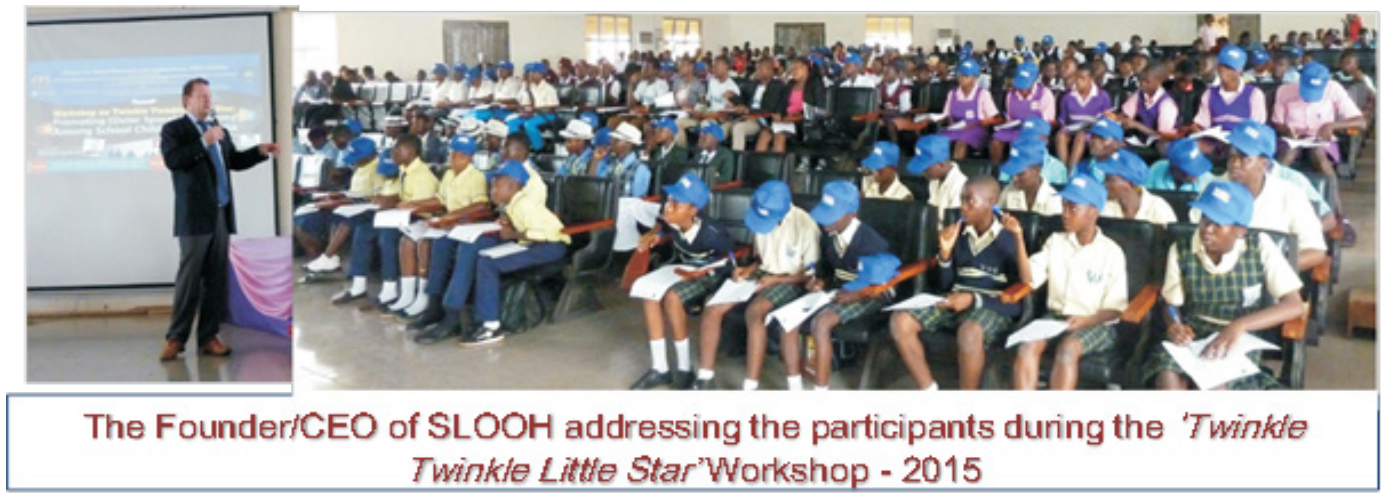

Figure 5. Twinkle Twinkle Little Star Workshop 


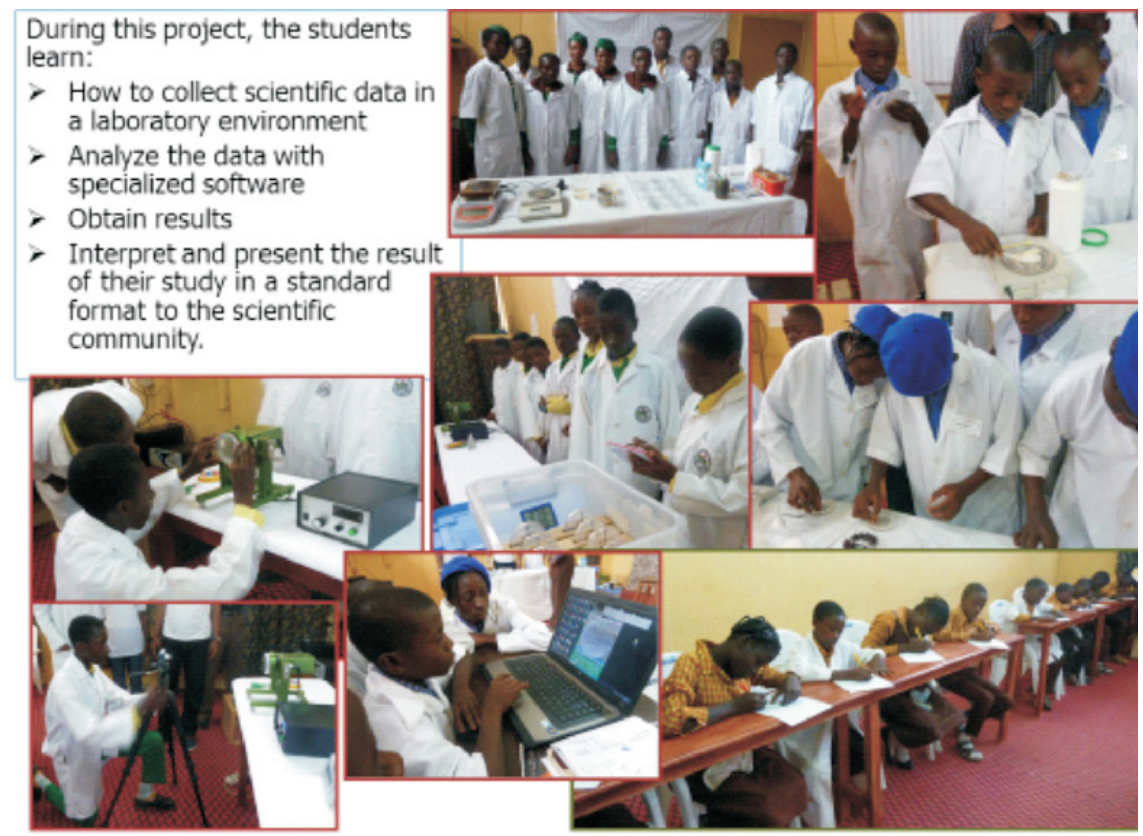

Figure 6. Participation in Human Zero-G

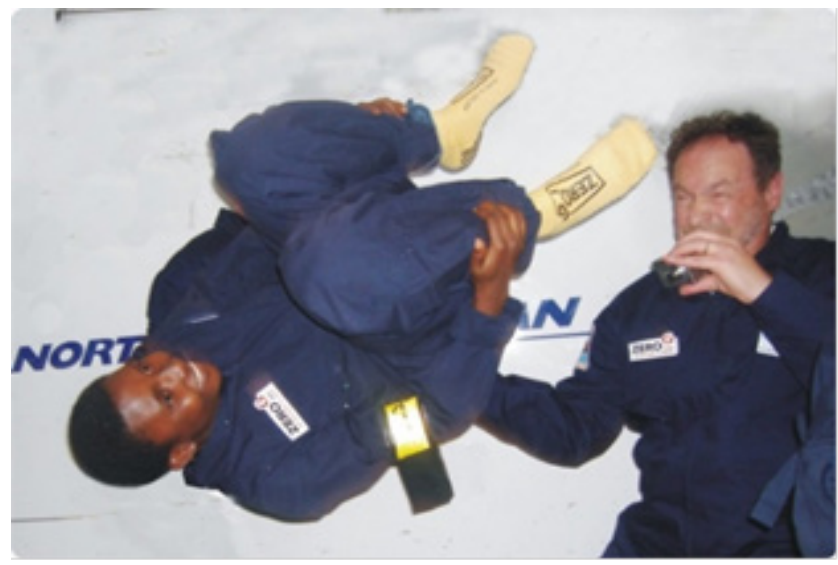

Figure 7. Zero-G Instrument Project

4.3.6. Development of Space Science Education for Primary and Secondary Schools

ARCSSTE-E has developed Curricula for space science education in primary and secondary schools in Nigeria through a committee of experts. The developed document was based on existing curricula and patterns in Nigeria. There are aspects of the Curricula that can be adopted both internationally and regionally taking cognisance of the prevailing educational curricula in each country.

\subsection{ARCSSTE-E Regional Bi-Annual Alumni Conferences}

ARCSSTE-E Regional Biennial Alumni Conference initiated in 2010 was designed as a forum for Alumni of the PGD programme of ARCSSTE-E to showcase how they have been able to successfully apply space science and technology for the socio-economic development of their home countries. It is also a re-union opportunity (Figure 8).

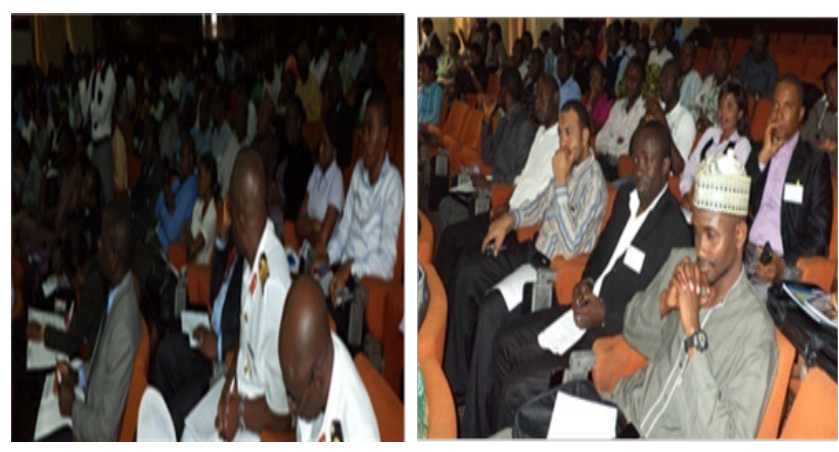

Figure 8. Bi-Annual Alumni Conference - an avenue to foster Regional Collaboration

\subsection{Regional Centers Capacity Building Collaboration/Short Training Workshops}

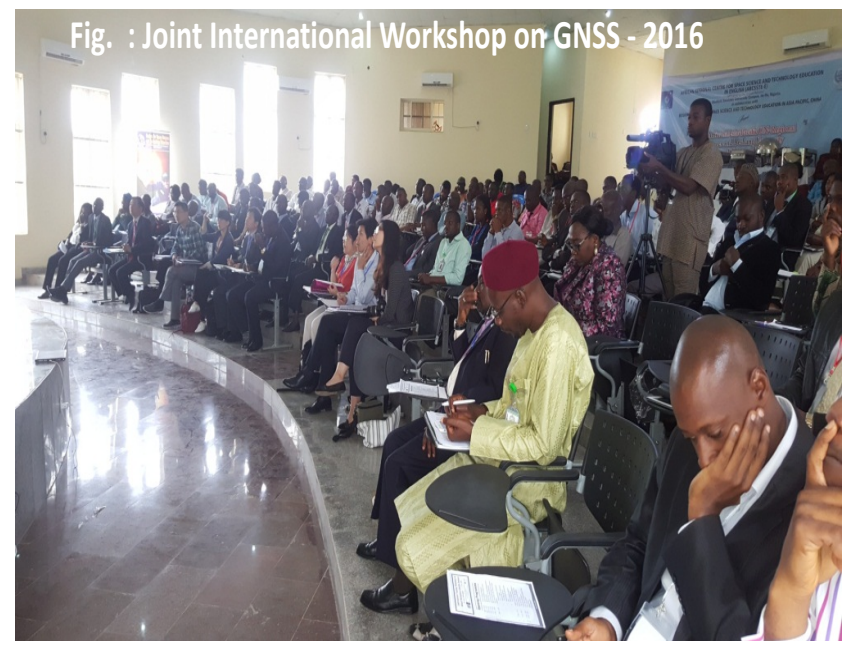

Figure 9. ARCSSTE-E, RCSSTEAP \& Beihang University, China International Workshop on GNSS 
To make participants aware of the potential of Satellite Navigation Technology and its applications with an emphasis on Location-Based Services and the principles and applications of Remote Sensing and GIS, the Centre carries out short training workshops on GNSS and Remote Sensing and GIS applications. In addition, ARCSSTE-E recently organized an International Training Workshop on GNSS in collaboration with the Regional Centre for Space Science and Technology Education for Asia-Pacific (RCSSTEAP) and Beihang University, Beijing, China, aimed at establishing and strengthening the capacity of users of GNSS technology and the Academia (Figure 9)

\section{Achievements So Far}

Some of the achievements of the Centre since inception can be highlighted as follows:

- Graduated over 404 participants at the Postgraduate Diploma level, using the UN-OOSA curricula;

- 46 participants successfully completed the M. Tech program;

- Over 1000 participants in short training programmes;

- Space Education Outreach/Awareness Programme for schools at all levels and the general public reaching over 10,000 school children, students and teachers and the general public;

- Integrated space-based research and development;

- National and International Capacity Building collaborations;

- Draft Space Science Education Curriculum for Primary and Secondary Schools

\section{Challenges Facing THE CENTRE}

\subsection{Funding}

Inadequate funding has been a major challenge in achieving the Centre's goals. In addition to the dwindling budgetary allocation of the Federal Government of Nigeria to the Centre, another major contributory factor to this is the non-remittance of Member State dues to the Centre. This has affected:

- Completion of the permanent site;

- Provision of modern and improved teaching aids;

- Inadequate ICT facilities including E-Library;

- Cross border cooperation with relevant national and international institutions for education, especially distance learning within the Anglophone African region.

\subsection{Collaboration for the Establishment of E-Learning Program}

To increase the number of beneficiaries of the programme, cooperation with relevant national and international institutions for cross border education, especially distance learning (E-Learning) within the Anglophone African region is now very necessary.

\subsection{Staff Internship and Secondment/Exchange of Teaching Staff}

There is need for more collaboration with relevant tertiary institutions across Member States and UN-affiliated Centres/UN observer bodies for staff internship and secondment/exchange of teaching staff.

\subsection{Establishment of Ground Receiving Station Facilities}

There is urgent need to have a Ground Receiving Station established in the Centre for teaching and research. The initial plan is to have GEONETCast receiving facilities.

\subsection{The Governing Board (GB)}

The Governing Board (GB) meetings which provide a veritable platform for Member countries to $\mathrm{x}$-ray the Centre's activities and programmes and also to proffer solutions to identified challenges was last held in 2014. ARCSSTE-E discovered that the statuses of some of the Member States representatives that do attend the meeting are in doubt. This has in a way affected the number of foreign participants in the Centre's programme has their representatives do not have the political clout to move the decisions of the Board forward in their respective countries.

\section{Conclusions}

The applications of Space Science and Technology (SS\&T) to socio-economic development within the African region are gaining wide acceptance with the emergence of more countries pursuing the development of one form of SS\&T programme or the other, depending on the individual country's level of investments.

There is a clear evidence of the impact of the UN-assisted capacity building programme which has already produced appreciable number of trained personnel as revealed in ARCSSTE-E's programme implementation and its achievements since its inception in November, 1998.

It is important that new strategies for capacity building at the formal and informal levels of education to train a sizeable number of experts to ensure meeting the SDGs 2030 be adopted. Those to be trained will include representatives of space industry, governmental and non-governmental organizations.

The need to develop indigenous capability in the space enterprise continues to be given a consideration in the Centre's capacity building programme. Education about space is a key strategy for training highly skilled scientists and engineers and it also inspires young people and the society at large.

ARCSSTE-E's Space Education Outreach programme has done a lot to generate genuine interest among the populace especially the youth in the society. However, commitment of Member States to the Regional Centre's activities is still very low and we believe that UN-OOSA can use her good offices 
to solve this problem. With better funding and collaboration among the Centres and other relevant international institutions, the aspirations of the UN-OOSA on the establishment of the Regional Centre - ARCSSTE-E would be met.

Capacity building, as well as enhancement and retention of existing capacity, are critical for developing Member States competencies to use Space Science and Technology efficiently for responding to societal challenges and addressing sustainable development. Utilising the opportunity presented by the establishment of two (2) UN affiliated Regional Centres in this field in Africa, will assist developing countries and regions in increasing their capacity and foster regional cooperation. It is therefore important that UNECA and AUC should ensure that the benefits accruing from these Centres are maximise and brought to the attention of Member nations.

\section{Table of Acronyms}

\begin{tabular}{|c|c|}
\hline Acronym & Meaning \\
\hline ARCSSTEE & $\begin{array}{l}\text { African Region Centre for Space Science and } \\
\text { Technology Education }\end{array}$ \\
\hline BSAS & Basic Space \& Atmospheric Science \\
\hline GNSS & Global Navigation Satellite Systems \\
\hline GB & The Governing Board \\
\hline MSST & $\begin{array}{l}\text { Masters programme in Space Science and } \\
\text { Technology }\end{array}$ \\
\hline NASRDA & National Space Research and Development Agency \\
\hline RCSSTEAP & $\begin{array}{l}\text { Regional Centre for Space Science and Technology } \\
\text { Education for Asia-Pacific }\end{array}$ \\
\hline REP & Robotics Education Program \\
\hline SST & Space Science and Technology \\
\hline SDGs & Sustainable Development Goals \\
\hline SEOP & Space Education Outreach Programme \\
\hline STEM & Science, Technology, Engineering and Maths \\
\hline UN-COPUOS & $\begin{array}{l}\text { United Nations Committee on Peaceful Uses of } \\
\text { Outer Space }\end{array}$ \\
\hline UNOOSA & United Nations Office for Outer Space Affairs \\
\hline UNISPACE & United Nations Space Conference \\
\hline UN-HSTI & United Nations Human Space Technology Initiative \\
\hline WSW & World Space Week \\
\hline ZGIP & Zero Gravity Instrument Project \\
\hline
\end{tabular}

\section{Acknowledgements}

Most of the Figures used in this paper are taken from ARCSSTE-E archive.

\section{REFERENCES}

[1] Haubold H. J., 2003a. Education Curricula of the UN-affiliated Regional Centres for Space Science and Technology Education, Space Policy, Vol. 19, pp. 67-69

[2] Haubold H. J., 2003b. Education curricula in space science and technology: the approach of the $\mathrm{UN}$-affiliated regional centres, Space Policy, Vol. 19, pp. 221-223

[3] United Nations, 1990. Resolutions and Decisions adopted by the General Assembly during its 45th Session: GAOR, 45th Session, Supplement No. 49, "International Co-operation in the Peaceful Uses of Outer Space", New York, USA, 18 September - 21 December 1990: A/45/49 (Vol.1) http://www.un.org/en/ga/search/view_doc.asp?symbol=A/RE S/45/72 (accessed 7 September 2016)

[4] United Nations, 1982. Resolutions and Decisions adopted by the General Assembly during its 37th session: GAOR, 37th Session, Supplement No. 51, "Second United Nations Conference on the Exploration and Peaceful Uses of Outer Space", New York, USA, 21

September - 21 December 1982 and 10-13 May 1983: A/37/51 http://www.un.org/en/ga/search/view doc.asp?symbol=A/RE S/37/90 (accessed 7 September 2016)

[1] United Nations, 1999a. Resolutions and Decisions adopted by the General Assembly during its 54th session: GAOR, 54th Session, Supplement No. 49, "International Co-operation in the Peaceful Uses of Outer Space", New York, USA, Volume I: Resolutions, 14 September - 23 December 1999: A/54/49 (Vol. I) + Corr.1 + Corr.2, http://www.un.org/en/ga/search/view_doc.asp?symbol=A/R ES/54/67 (accessed 7 September 2016) A/54/PV.71

[5] United Nations, 1999b. Report of the Third United Nations Conference on Exploration and Peaceful Uses of Outer Space Vienna, UN General assembly 19-30 July 1999 http://www.worldspaceweek.org/uploads/UNISPACEIII_AC ONF184_6E.pdf

[6] UNCED, 1992. United Nations Conference on Environment and Development ''Rio de Earth Summit, June 3 -14, 1992 in Rio de Janeiro. 